\title{
Storm-time longitudinally propagating asymmetric modes at low latitudes
}

\author{
A. K. Singh ${ }^{1}$, A. K. Sinha ${ }^{1}$, R. Rajaram ${ }^{1,2}$, and B. M. Pathan ${ }^{1}$ \\ ${ }^{1}$ Indian Institute of Geomagnetism, Kalamboli Highway, New Panvel (W), Navi Mumbai - 410218, Maharashtra, India \\ ${ }^{2}$ Micro Technologies (India) Ltd., MIDC, Mahape, Navi Mumbai - 400709, Maharashtra, India \\ Correspondence to: A. K. Singh (singhaaks@gmail.com)
}

Received: 6 September 2011 - Revised: 8 November 2011 - Accepted: 12 November 2011 - Published: 13 January 2012

\begin{abstract}
The westward flowing toroidal ring current at about 2-7 $R_{\mathrm{E}}$ in the Earth's equatorial plane consists of symmetric and asymmetric parts. Zonal mean of $H$ disturbances from longitudinally distributed low latitude stations represents the symmetric contribution, whereas departure from the zonal mean gives local time dependent asymmetric component at each of the stations. Through a standard analysis of closely spaced low latitude geomagnetic data we demonstrate $24 \mathrm{~h}$ periodicity in the asymmetric component of the storm-time ring current, which is related to the changing local time due to rotation of the Earth. Detailed examination of shorter period oscillations, when observed globally, often show westward propagating modes. Eastward propagating mode was also observed in one case. Based on satellite and radar observations covering a narrow longitude region, westward and eastward propagating modes had been reported in earlier studies. In this study, we report that similar propagating modes which are available on global scale, can be identified using ground-based magnetometer data. These globally propagating modes, observed from ground-based studies, find obvious practical application in diagnostics of the magnetosphere, especially the ring current region. Simultaneous use of satellite and ground-based data should establish the morphology of such modes.
\end{abstract}

Keywords. Magnetospheric physics (Energetic particles, trapped; Solar wind-magnetosphere interactions; Storms and substorms)

\section{Introduction}

The Earth's magnetosphere is a natural consequence of highspeed solar wind compressing the geomagnetic field on the dayside and stretching it out on the night side in the form of long geomagnetic tail (Walker and Russell, 1995). In the inner magnetosphere, energetic electrons and ions are trapped within the closed geomagnetic field line geometry (Wolf, 1995). These energetic particles drift around the Earth - protons drift in the westward direction and electrons drift in the eastward direction due to gradient and curvature in the magnetic field. Drifting energetic charged particles set up the ring current close to the equatorial plane in the magnetosphere. The ring current generates a magnetic field that can be detected by satellites in space as well as ground geomagnetic observatories spread over the globe (Sugiura, 1964; Williams, 1985).

Low latitude magnetic observatory data have been regularly used to monitor the ring current in the magnetosphere (Sugiura, 1964; Iyemori, 1990). The zonal mean of $H$ disturbance observed at a set of low latitude stations gives Dst or SYMH indices which represent the symmetric component of the ring current. However, the ring current can become highly asymmetric in local time during magnetic storms. Departure of $H$ disturbance at each of the stations from the zonal mean gives local time dependent asymmetric time series. An asymmetric index, ASYH, is further defined as the difference of the maximum and the minimum values of asymmetric time series over all the longitudes at that instant (Iyemori, 1990).

The spatio-temporal characteristics of the ring current have been extensively investigated by means of ground and satellite-based observations (e.g. Akasofu and Chapman, 
Table 1. List of ground stations and their geographic and magnetic coordinates.

\begin{tabular}{|c|c|c|c|c|c|}
\hline \multirow{2}{*}{$\begin{array}{l}\text { Station } \\
\text { name }\end{array}$} & \multirow[b]{2}{*}{ Code } & \multicolumn{2}{|c|}{ Geographic } & \multicolumn{2}{|c|}{ Magnetic } \\
\hline & & $\begin{array}{l}\text { lat. } \\
\left({ }^{\circ} \mathrm{N}\right)\end{array}$ & $\begin{array}{l}\text { long. } \\
\left({ }^{\circ} \mathrm{E}\right)\end{array}$ & $\begin{array}{l}\text { lat. } \\
\left({ }^{\circ} \mathrm{N}\right)\end{array}$ & $\begin{array}{l}\text { long. } \\
\left({ }^{\circ} \mathrm{E}\right)\end{array}$ \\
\hline Del Rio & DLR & 29.5 & 259.1 & 38.8 & 326.7 \\
\hline Pamatai & PPT & -17.6 & 210.4 & -16.7 & 285.4 \\
\hline Honolulu & $\mathrm{HON}$ & 21.3 & 202.0 & 21.3 & 270.0 \\
\hline Kakioka & KAK & 36.2 & 140.2 & 29.3 & 212.0 \\
\hline Kanoya & KNY & 31.4 & 130.9 & 24.7 & 203.1 \\
\hline Zhaoqing & GZH & 23.0 & 112.4 & 16.5 & 185.3 \\
\hline Phu Thuy & PHU & 21.0 & 106.0 & 14.2 & 177.9 \\
\hline Alibag & $\mathrm{ABG}$ & 18.6 & 72.9 & 12.1 & 145.4 \\
\hline Hermanus & HER & -34.4 & 19.2 & -42.4 & 83.0 \\
\hline Guimar & ASC & -8.0 & 345.6 & 17.2 & 60.5 \\
\hline San Juan & SJG & 18.1 & 293.9 & 27.5 & 10.8 \\
\hline
\end{tabular}

1964; Cummings, 1966; Frank, 1970; Love and Gannon, 2010). A remarkable dawn-dusk asymmetry is often observed during main phases of magnetic storms, which is attributed to the partial ring current on the dusk side of the Earth (Akasofu and Chapman, 1964).

Azimuthally propagating ultra low frequency (ULF) waves have been observed in the equatorial plane of the Earth's magnetosphere using satellite-based magnetic and particle observations as well as ground-based radar electric field measurements. For example, Walker et al. (1982); Lin and Barfield (1985); Takahashi et al. (1985) presented observations of Pc5 waves propagating in the direction of drift of the guiding-centre of positive charged particles, i.e. westward in longitude. Moreover, eastward propagating waves were also observed by STARE radar observations (Walker and Nielsen, 1984) and satellite observations (Lin and Barfield, 1985; Takahashi et al., 1987). Drift-mirror modes generated due to pressure gradient in the ring current region were proposed to explain the azimuthally propagating waves (Hasegawa, 1969; Walker et al., 1982). In addition, Alfvénballooning modes also can have longitudinal phase velocity in the ion diamagnetic direction (Takahashi, 1988; Chan et al., 1994).

The longitudinally propagating modes reported earlier were observed by a pair of geosynchronous satellites separated by about $2^{\circ}-30^{\circ}$ longitude (Walker et al., 1982; Lin and Barfield, 1985; Takahashi et al., 1985) or in the narrow field of view of radar around $400 \mathrm{~km} \times 400 \mathrm{~km}$ (Allan et al., 1982; Walker and Nielsen, 1984). However, the circumferential modes in the frequency regime of drift waves generated in the magnetosphere have not been observed using ground magnetic field observations. We use the standard procedures to generate the symmetric and asymmetric components of the ring current contributions. The modes are often westward propagating but we also have an example of an eastward propagating mode. We are inclined to believe that the westward propagating modes could be associated with ion drift or ballooning modes while the eastward propagating modes could be associated with electron drift.

In Sect. 2, details of data set used in this study and methodology are provided. In Sect. 3 we present the observational results and Sect. 4 gives an account of discussion and conclusions.

\section{Data set and methodology}

We use one minute averages of the horizontal component, $H$, at the low latitude INTERMAGNET observatories distributed around the globe, but at the same time outside the influence of highly variable auroral as well as equatorial currents in the ionosphere. This ensures that influence of ionospheric fluctuations is limited and we are essentially looking at magnetic field variations produced by currents in the magnetosphere. Details of ground observatories used in this study are given in Table 1. The magnetic latitude and longitude of observatories were taken from SuperMAG (http://supermag.jhuapl.edu/).

Here, the standard techniques adopted for ring current Dst indices (Sugiura, 1964; Iyemori, 1990) have been used except for the fact that we have taken one minute values instead of hourly averages. There are three steps involved, namely

1. Calculation of the mean $H$ at each station for every local time (LT) instant for the five international quiet days in the month. Tacitly assuming that this is a reasonable estimate for the contribution of ionospheric currents for every day in the month considered, we can subtract it out from the magnetic field data for each of the observatories. What is left over should be an estimate $\delta H$ of the contribution from the magnetosphere towards the one minute sampled magnetic field variations at each observatory.

2. $\delta H$ is the component of the variations tangential to the surface of the Earth and varies with latitude of the station. We are looking for oscillations due to the currents in the ring current region, which will be normal to the equatorial plane. We divide the $\delta H$ variations at each minute by the cosine of the magnetic latitude of the observatory to obtain $\Delta H$, an estimate of the contribution of the ring current at the latitude of the observatory.

3. The $\Delta H$ time series can be used to define various indices characterizing the ring current. The zonal mean of $\Delta H$ time series is termed as SYMH, which is the index of the ring current strength at that instant (Sugiura, 1964; Iyemori, 1990). The asymmetric field $\Delta H_{\text {asym }}$ at each observatory is defined as the departure from the zonal mean. This is obtained by subtracting SYMH from the instantaneous value of $\Delta H$ at that station. 

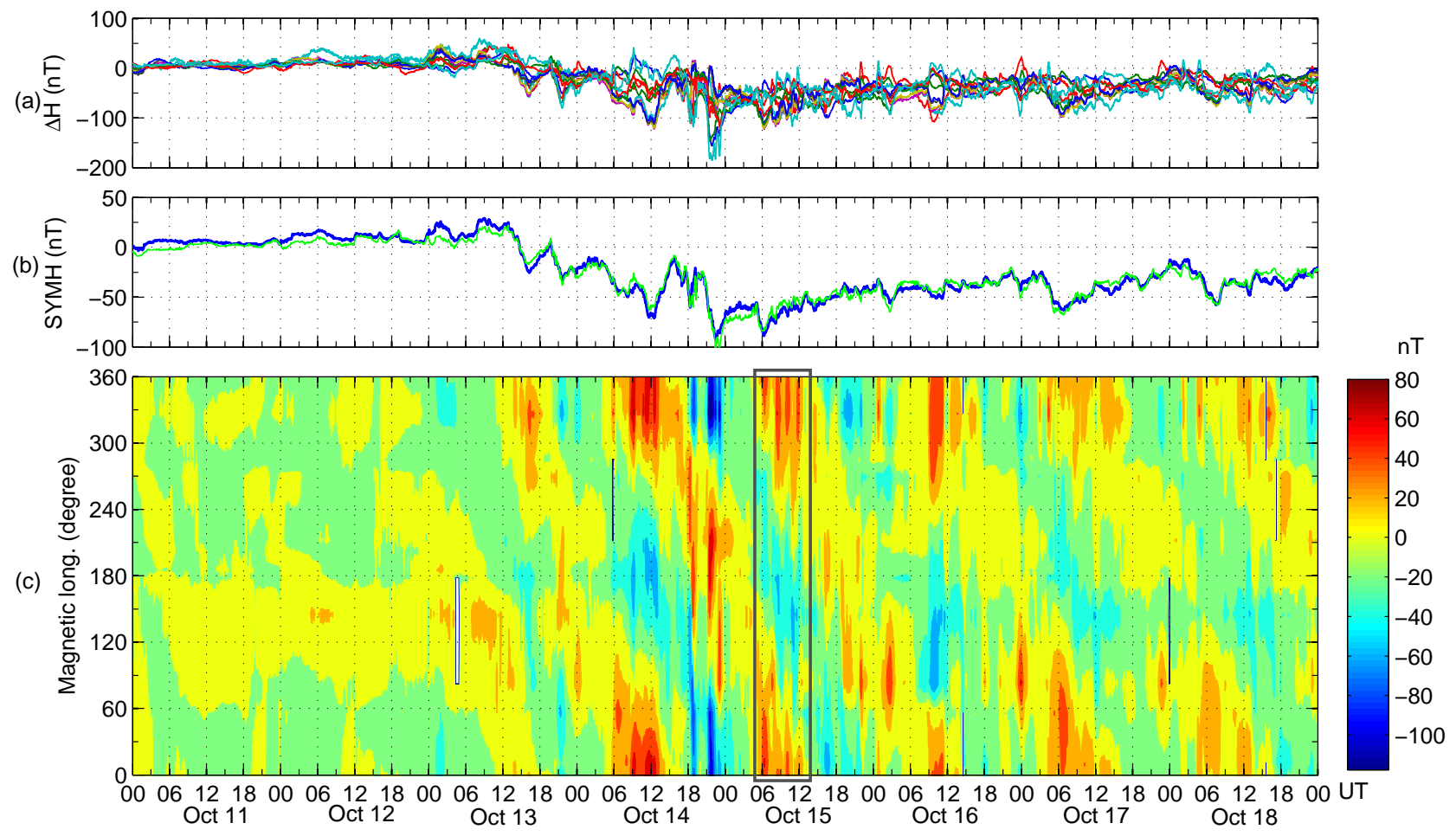

Fig. 1. $\Delta H$ disturbance, SYMH index and longitude propagation of asymmetric disturbance $\Delta H_{\text {asym }}$ during $11-18$ October 2003. (a) Traces of different colours represent $\Delta H$ observed at longitudinally distributed 11 stations and (b) thick blue line represents zonal mean of $\Delta H$, i.e. equivalent SYMH, whereas green line represents SYMH provided by WDC, Kyoto. SYMH calculated using data of 11 stations and 5-6 stations show fairly similar variations. (c) X-axis represents time in UT, Y-axis represents magnetic longitude and the $\Delta H_{\text {asym }}$ observed at stations has been colour-coded. A clear $24 \mathrm{~h}$ periodicity in the asymmetric disturbance is evident due to changing local time on the Earth. The grey rectangle shows the duration selected for detailed examination.

This instantaneous value often varies with the longitude of the station, especially during magnetic storms. An asymmetric index (ASYH) can be defined as the difference of the maximum and the minimum values of $\Delta H_{\text {asym }}$ over all the longitudes at that instant (Iyemori, 1990).

In the following section, we first present the longitudinal characteristic of asymmetric field $\left(\Delta H_{\text {asym }}\right)$ for a moderate storm that started on 13 October 2003. Next, we investigate the finer details of magnetic oscillations present globally during the storm and demonstrate clear longitudinal propagation of these modes.

\section{Observational results}

The top panel of Fig. 1 shows the $\Delta H$ time series (in different colours) observed at longitudinally distributed 11 stations during 11-18 October 2003. For better longitude resolution we selected some more closely spaced stations in addition to standard Dst and SYM-ASY stations. The mean of $\Delta H$ gives the equivalent SYMH index as shown in Fig. 1b by thick blue line. The green lines shown in the same panel is
SYMH index provided by WDC, Kyoto. It is clear from the figure that the SYMH, calculated using magnetic data from 5-6 stations and 11 stations, are fairly similar.

A moderate magnetic storm (minimum value of standard Dst $=-85 \mathrm{nT}$ ) started on 13 October after a typical storm sudden commencement. The $H$ field was globally depressed and it took several days for the storm to recover. Contour plot of asymmetric field $\Delta H_{\text {asym }}$ with magnetic longitude on Yaxis and universal time (UT) on X-axis is shown in Fig. 1c. For 11 selected INTERMAGNET stations, magnetic longitudes extend from $10.8^{\circ}$ (SJG) to $326.7^{\circ}$ (DLR). In order to avoid spurious impression at top and bottom edges of figure, all the contour plots presented in the paper are generated from $10.8^{\circ}$ to $3 \times 326.7^{\circ}$ magnetic longitude by repeating the data. Finally, we present plots for one complete cycle of longitude.

It is well known that the ring current becomes asymmetric in local time during magnetic storms, often more prominent on the dusk side of the Earth (Akasofu and Chapman, 1964; Love and Gannon, 2010). The effect of changing local time at a given location due to the rotation of the Earth is clearly seen in Fig. 1c. Around 12:00 UT, stations near $0^{\circ}$ (or $360^{\circ}$ ) longitude are on the dawn side of the Earth, whereas those 
(a) $\mathrm{H}$ disturbance at low latitude stations (in $\mathrm{nT}$ )

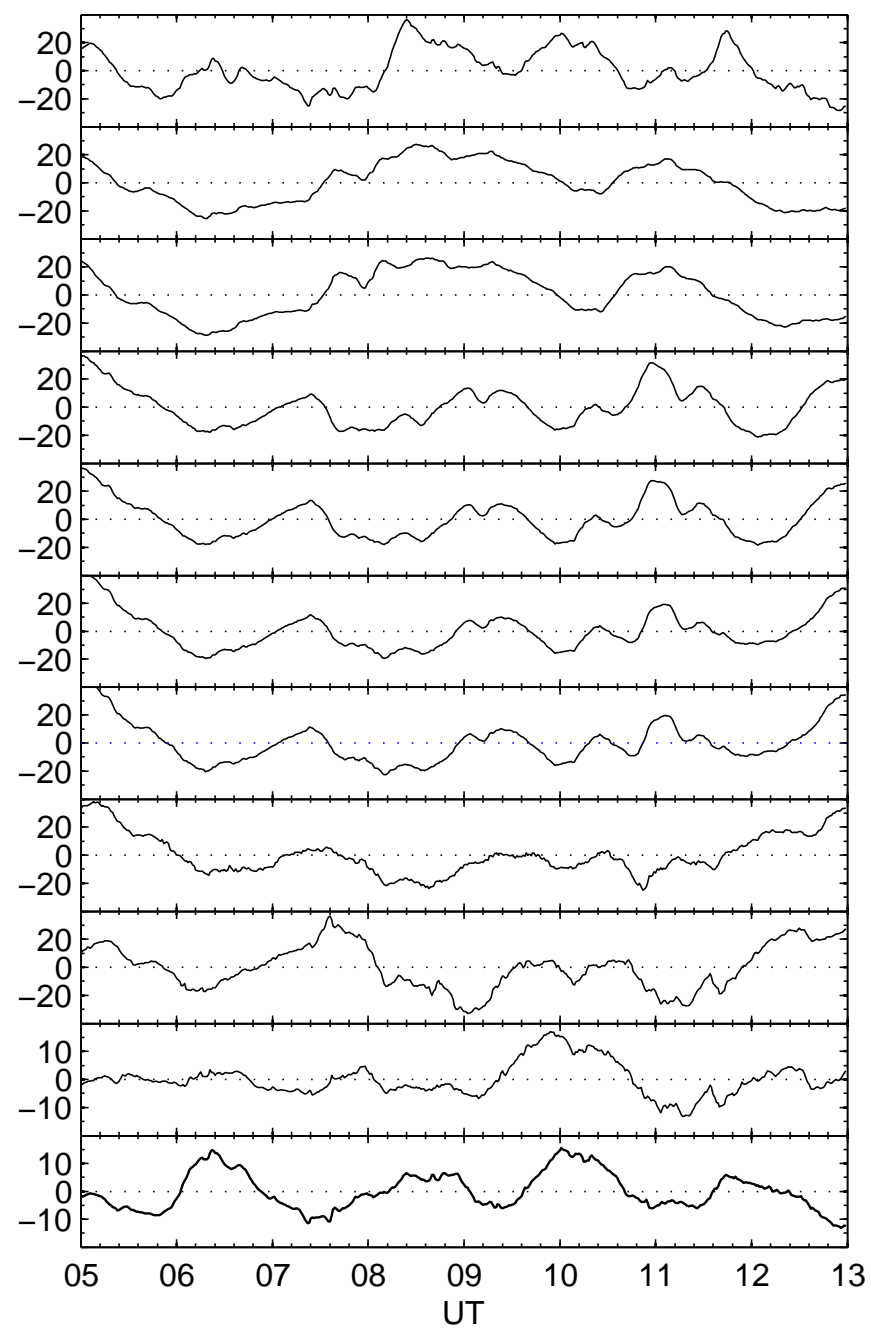

(b) PSD (arbitrary units)

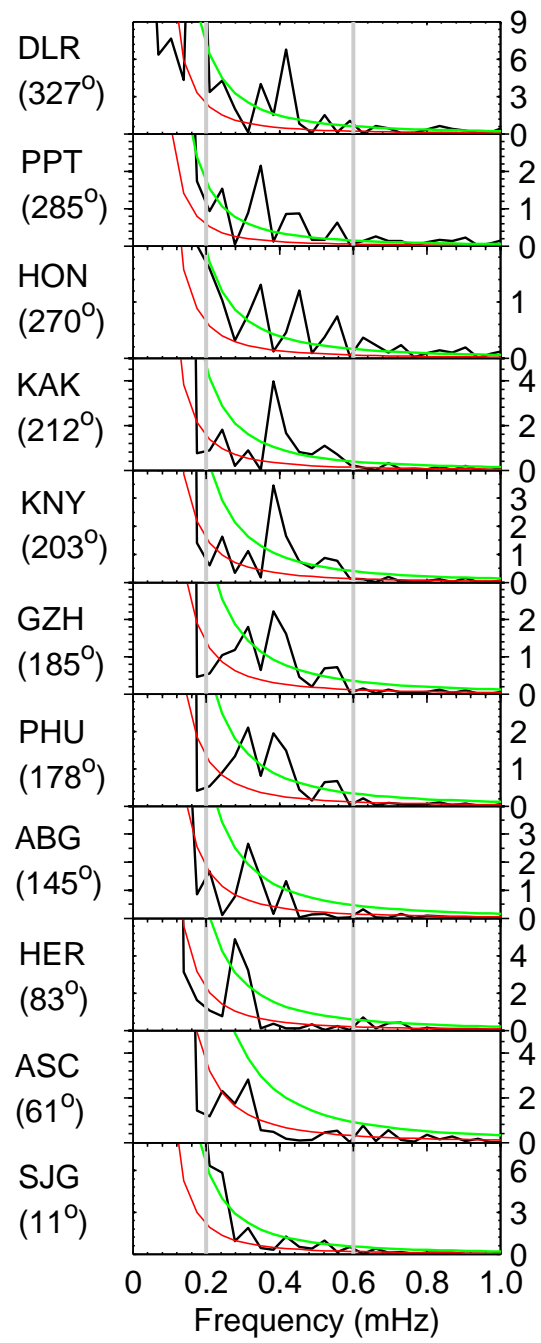

Fig. 2. $\Delta H$ disturbance and FFT power spectra during 05:00-13:00 UT on 15 October 2003. (a) $\Delta H$ disturbance after removing the linear trend at longitudinally distributed 11 low latitude stations. Codes of stations and magnetic longitudes are given on the right side of the subplots. (b) Normalized power spectral density of $\Delta H$, mean red noise power (red curve) and $95 \%$ confidence level (green curve) at corresponding stations show globally high power in frequency band $0.2-0.6 \mathrm{mHz}$ (marked between pair of grey vertical lines).

near $180^{\circ}$ longitude lie on the dusk side. It is evident from the figure that stations on the dawn side show $\Delta H_{\text {asym }}$ values higher than the zonal mean (red colour), whereas on the dusk side $\Delta H_{\text {asym }}$ values are smaller than the mean (blue colour). Due to the rotation of the Earth, local time changes at a given longitude and the asymmetry appears moving with a period of around $24 \mathrm{~h}$.

Next, we examine a relatively shorter time duration 05:0013:00 UT on 15 October 2003 selected on the basis of similar global scale oscillations and persistent spectral peaks in power spectra. This duration is shown by grey rectangle in Fig. 1c. $\Delta H$ values as well as their spectra during this time interval are depicted in Fig. 2a and b, respectively. It is evident from Fig. 2a that magnetic disturbances of various temporal scales were globally observed during the event. Power spectra of $\Delta H$ on the right side clearly show globally high power in the spectral band $\sim 0.2-0.6 \mathrm{mHz}$, i.e. period range $\sim 28-83$ min (marked between two vertical grey lines) at 9 stations above $95 \%$ confidence level (shown by green line). The red lines in subplots show mean red noise power.

We present the interplanetary magnetic field (IMF) and the solar wind conditions during the selected time interval in Fig. 3. The north-south component of the interplanetary magnetic field, IMF $B_{\mathrm{Z}}$ and the solar wind density $\left(N_{\mathrm{sw}}\right)$ variations (as observed by ACE satellite located at $X \simeq 226 R_{\mathrm{E}}$, $Y \simeq 19 R_{\mathrm{E}}, Z \simeq-38 R_{\mathrm{E}}$ in GSM coordinates) are shown in Fig. 3a during 05:00-13:00 UT on 15 October 2003. The interplanetary observations are time-shifted by 35 min taking into account the travel time of the solar wind at an average propagation speed of $\sim 682 \mathrm{~km} \mathrm{~s}^{-1}$ from the location of the 
(a)

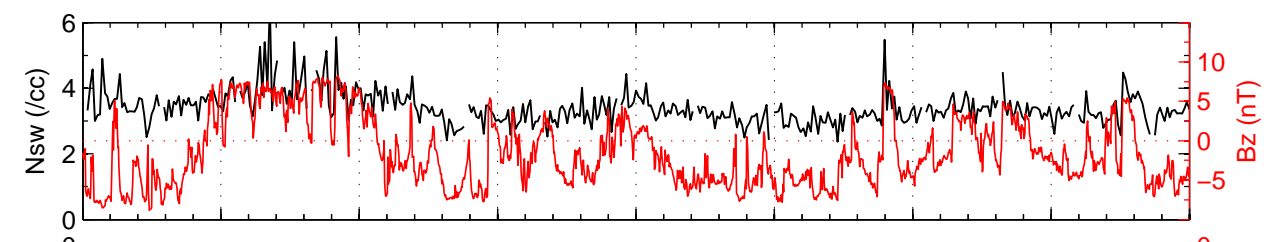

(b)
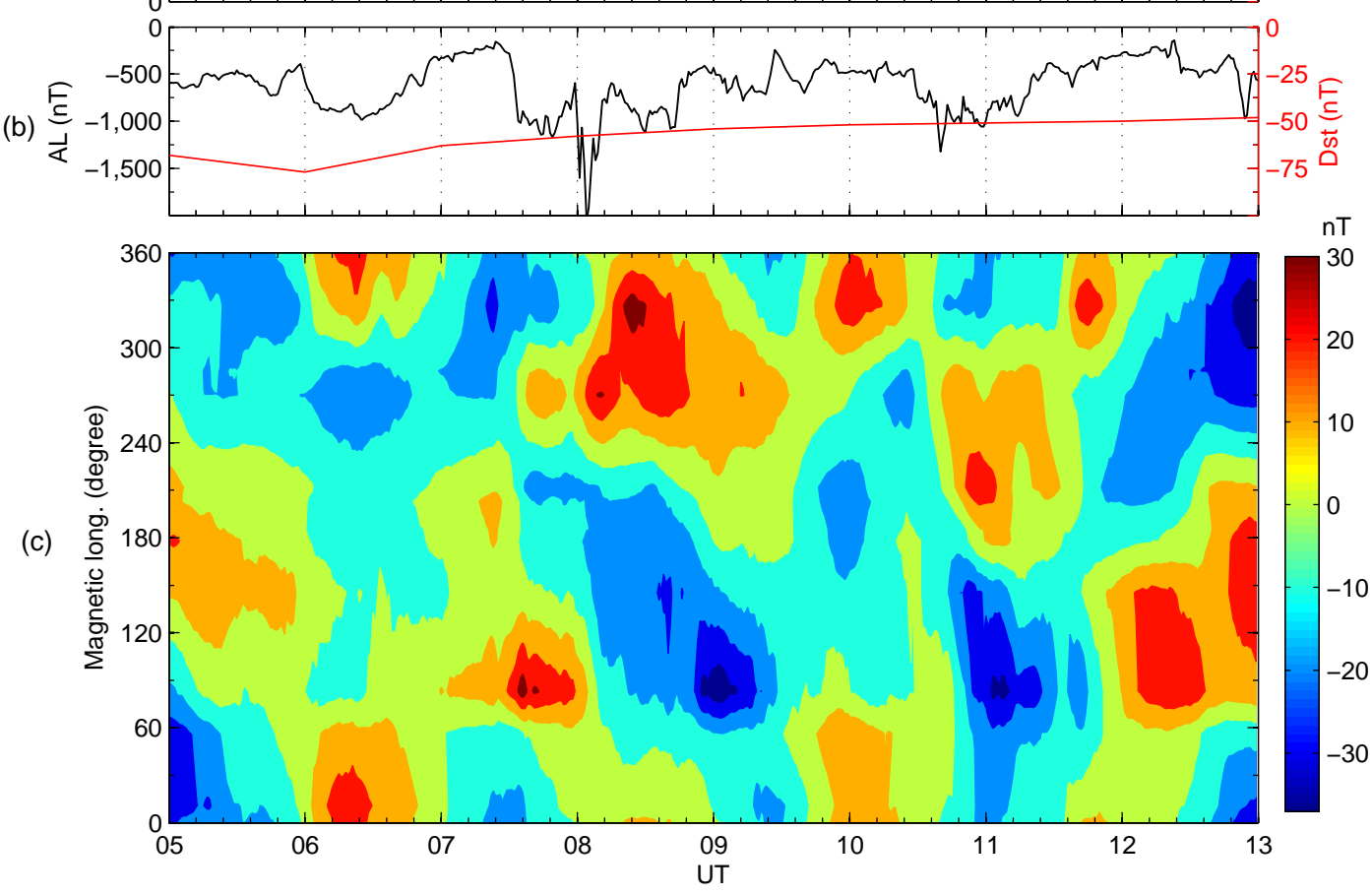

Fig. 3. Solar wind density $\left(N_{\mathrm{SW}}\right)$ and IMF $B_{\mathrm{Z}}$ fluctuations and ground magnetic disturbance on 15 October 2003. (a) IMF $B_{\mathrm{Z}}$ (shown in red) fluctuates between $\pm 10 \mathrm{nT}$, whereas $N_{\mathrm{sw}}$ (black line) is relatively steady during the event. (b) Hourly Dst index (red) shows a moderate storm was in progress and various intense substorm were triggered as indicated by AL index shown in black. (c) Contour plot of $\Delta H_{\mathrm{asym}}$ indicates disturbance propagating westward in longitude.

satellite to the ground. As shown in Fig. 3a, $N_{\mathrm{sw}}$ is relatively steady and IMF $B_{\mathrm{Z}}$ varies between $\pm 10 \mathrm{nT}$. Intense substorm activities were observed during the early recovery phase of a moderate geomagnetic storm (minimum Dst $\simeq-85 \mathrm{nT}$ ) as shown in Fig. 3b. Contour plot of $\Delta H_{\text {asym }}$ in the raw data (Fig. 3c) hints at the presence of westward propagating disturbance.

To map the propagation characteristics of the mode described in Fig. $2 \mathrm{~b}$, we pass the $\Delta H$ time series through a Butterworth bandpass filter that allows fluctuations in the frequency range $0.2-0.6 \mathrm{mHz}$ to go through and then compute the $\Delta H_{\text {asym }}$ for this oscillation using step 3 discussed in Sect. 2. The magnetic longitude profile of propagation of $\Delta H_{\text {asym }}$ during 05:00-13:00 UT is depicted in Fig. 4. In the beginning of the event, propagation is rather random, but after $\sim 09: 30$ UT we see a clear westward propagation of the mode. The broken lines after 09:30 UT in the figure indicate that the apparent westward propagation speed $\left(V_{\mathrm{ap}}\right)$ is around $360^{\circ} / \mathrm{h}$. After $\sim 12: 00$ UT amplitude of the wave drops considerably. However, the westward propagation continues further for some more cycles.
Having observed clear signatures of westward propagating mode in the above event, we are curious to know whether similar modes are present during other storm like conditions and whether it is possible to detect eastward propagating mode as well. We present some more events when longitude propagation of modes were clearly observed during magnetic storms. For identification of events which exhibit longitudinally propagating waves, three-year (2003-2005) geomagnetic data were visually scanned for similar oscillations in $H$ disturbance over a wide range of longitude during storm-time moderate to intense substorm activities. Events that exhibit high power in similar spectral band over all the longitudes were considered for further investigation of longitude propagation characteristics. We list six such selected events and respective geomagnetic conditions in Table 2 which includes the event of 15 October 2003 described earlier. Out of the six listed events, five were westward propagating while the event of 31 October 2003 showed eastward propagation. Identified events, categorized under two heads, viz. (1) westward propagating events and (2) eastward propagating events, have been discussed below. 


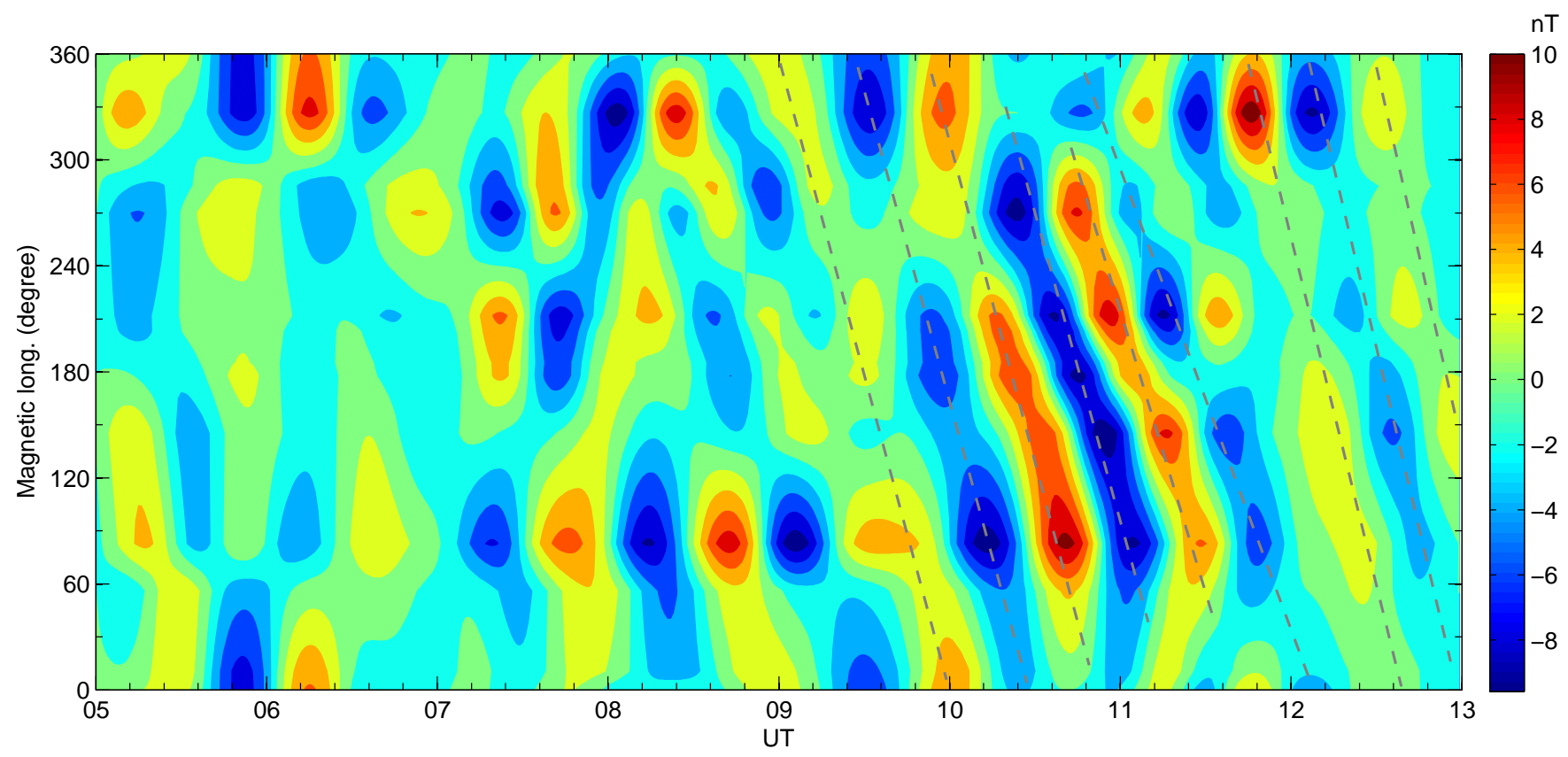

Fig. 4. Contour plot of asymmetric disturbance, $\Delta H_{\text {asym }}$ in the spectral band $0.2-0.6 \mathrm{mHz}$ shows several cycles of westward propagating mode after 09:30 UT (indicated by slanted dashed lines). The X-axis represents time in UT, the Y-axis represents the magnetic longitude and the amplitude of disturbance (in nT) is colour coded.

Table 2. List of events showing westward/eastward propagating modes.

\begin{tabular}{ccccc}
\hline Date & Duration & Minimum Dst (nT) & Minimum AL (nT) & Propagation \\
\hline 15 October 2003 & $09: 30-13: 00$ UT & -58 & -1320 & Westward \\
31 October 2003 & $12: 06-13: 15$ UT & -77 & -990 & Eastward \\
25 January 2004 & $19: 00-22: 00$ UT & -72 & -500 & Westward \\
2 January 2005 & $15: 30-18: 30$ UT & -41 & -1475 & Westward \\
19 January 2005 & $12: 30-14: 00$ UT & -85 & -1400 & Westward \\
6 March 2005 & $15: 00-16: 30$ UT & -60 & -1100 & Westward \\
\hline
\end{tabular}

\subsection{Westward propagating events}

For the sake of brevity, we do not show the IMF conditions, geomagnetic indices and longitude propagation of $\Delta H_{\text {asym }}$ in the raw data for the rest of the events propagating westward in longitude. In Fig. 5 we show the longitude propagation of $\Delta H_{\text {asym }}$ of disturbances in the dominant frequency band for four different events and power spectra of $\Delta H$ at two representative stations HER and HON separated by about $180^{\circ}$ longitude. The dominant frequency bands for these four events have been marked by a pair of grey vertical lines in the representative spectra. It should be noted that other stations also show similar and persistent spectral peaks in the mentioned frequency band.

\subsubsection{January 2005 event}

Intense substorm activities during a moderate geomagnetic storm (Dst $\simeq-85 \mathrm{nT})$ generated global magnetic perturbations in the time interval 11:30-15:00 UT. Power spectra of $\Delta H$ revealed significantly high power in the spectral band $0.5-0.9 \mathrm{mHz}$ at stations listed in Table 1. Right panel of Fig. 5a demonstrates power spectra of $\Delta H$ and $95 \%$ confidence level for two representative stations HER and HON.

We bandpass the $\Delta H$ time series in frequency range $0.5-0.9 \mathrm{mHz}$ (period range $\sim 18-33 \mathrm{~min}$ ) and then compute the $\Delta H_{\text {asym }}$ for this oscillation. The magnetic longitude profile of propagation of $\Delta H_{\text {asym }}$ during 11:30-15:00 UT is depicted in left panel of Fig. 5a. After 12:30 UT, we see a clear westward propagation of the disturbances with $V_{\text {ap }} \sim 360^{\circ} / 30 \mathrm{~min}$ in this case, which has considerably high amplitude till $\sim$ 14:00 UT. The cycle persists even beyond 14:00 UT but with diminishing amplitude. 

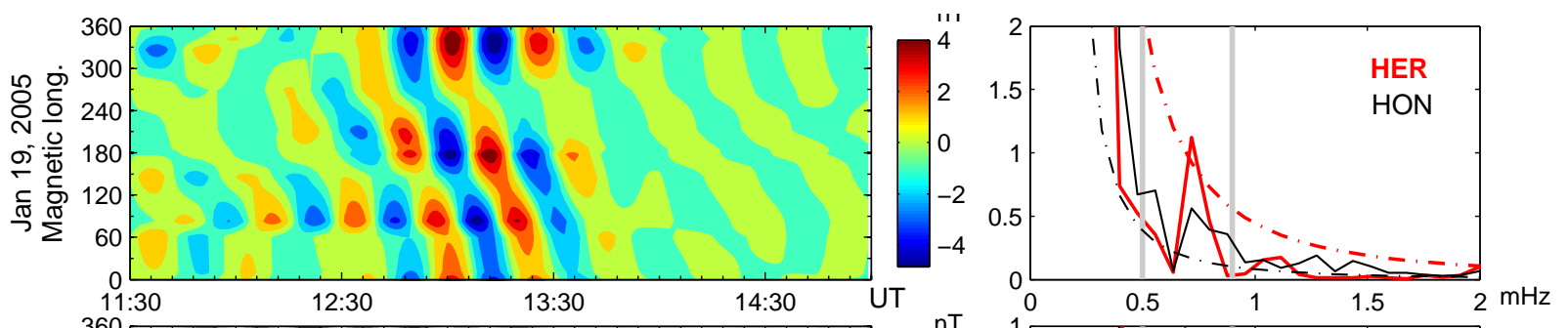

(b)
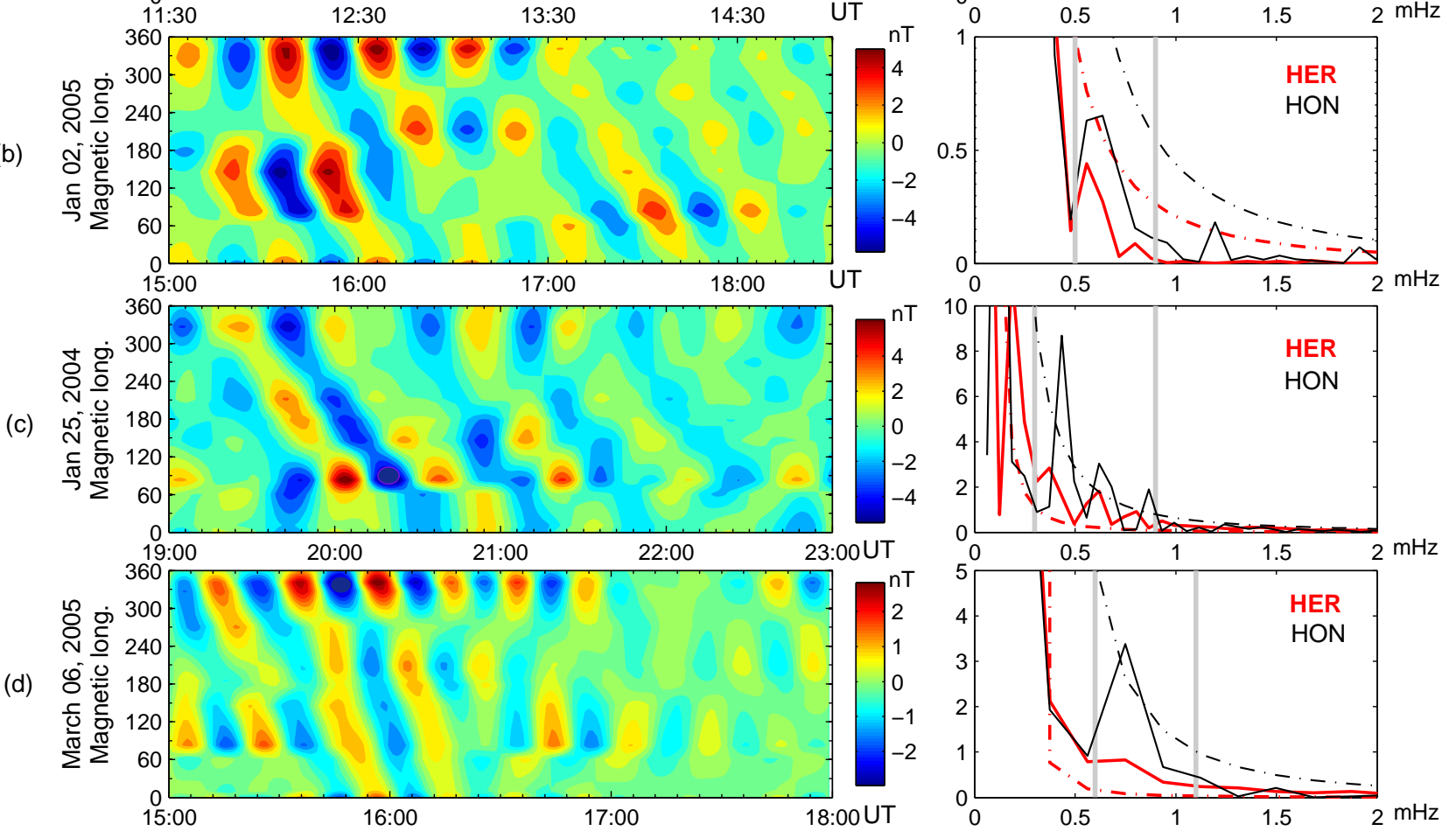

Fig. 5. Contour plot of longitudinal propagation of $\Delta H_{\text {asym }}$ and PSD of $\Delta H$ at two representative stations HER and HON separated by $\sim 180^{\circ}$ longitude on (a) 19 January 2005 in frequency range $0.5-0.9 \mathrm{mHz}$, (b) 2 January 2005 in frequency range $0.5-0.9 \mathrm{mHz}$, (c) $25 \mathrm{Jan}-$ uary 2004 in frequency range $0.3-0.9 \mathrm{mHz}$ and (d) 5 March 2005 in frequency range $0.6-1.1 \mathrm{mHz}$.

\subsubsection{January 2005 event}

A high speed stream of solar wind buffeted the Earth's magnetosphere on 2 January 2005, which resulted in intensification of the ring current (minimum Dst $\simeq-50 \mathrm{nT}$ ) and various intense substorms on the day. During 15:00-18:30 UT an intense substorm $(\mathrm{AL} \simeq-1500 \mathrm{nT})$ generated global magnetic perturbations in the frequency range $\sim 0.5-0.9 \mathrm{mHz}$. Power spectra in the right panel of Fig. 5b demonstrate peaks at stations HER and HON in the same frequency band marked between two vertical grey lines. It should be noted that the spectral peaks (shown for stations HER and HON) are below $95 \%$ confidence level. At stations, e.g. SJG, DLR, PPT the spectral peaks were significant above $95 \%$ confidence level, but for the sake of uniformity with other events spectra for HER and HON have been presented. In addition to the confidence level, persistence of spectral peak over a wide range of longitude is an important criterion that must be taken into account.
The magnetic longitude profile of propagation of $\Delta H_{\text {asym }}$ for this mode is depicted in the left panel of Fig. 5b. A clear westward propagating mode with $V_{\text {ap }} \sim 360^{\circ} / 30 \mathrm{~min}$ is evident from the observation. The propagation persists for around $3 \mathrm{~h}$ (15:30-18:15 UT).

\subsubsection{January 2004 event}

A moderate storm (Dst $\simeq-72 \mathrm{nT}$ ) was in progress on $25 \mathrm{Jan}$ uary 2004 and during the substorm $(\mathrm{AL} \simeq-500 \mathrm{nT})$ in the time interval 19:00-23:00 UT, oscillations in the frequency range $0.3-0.9 \mathrm{mHz}$ (period range $\sim 18-55 \mathrm{~min}$ ) were globally observed in $\Delta H$ disturbance. Westward propagation of $\Delta H_{\text {asym }}$ with $V_{\text {ap }} \sim 360^{\circ} / 35 \mathrm{~min}$ is explicitly observed as depicted in Fig. 5c. The power spectra of $\Delta H$ observed at two representative stations HER and HON are shown in the right panel of the figure. 
(a) $\Delta \mathrm{H}$ disturbance at low latitude stations (in nT)

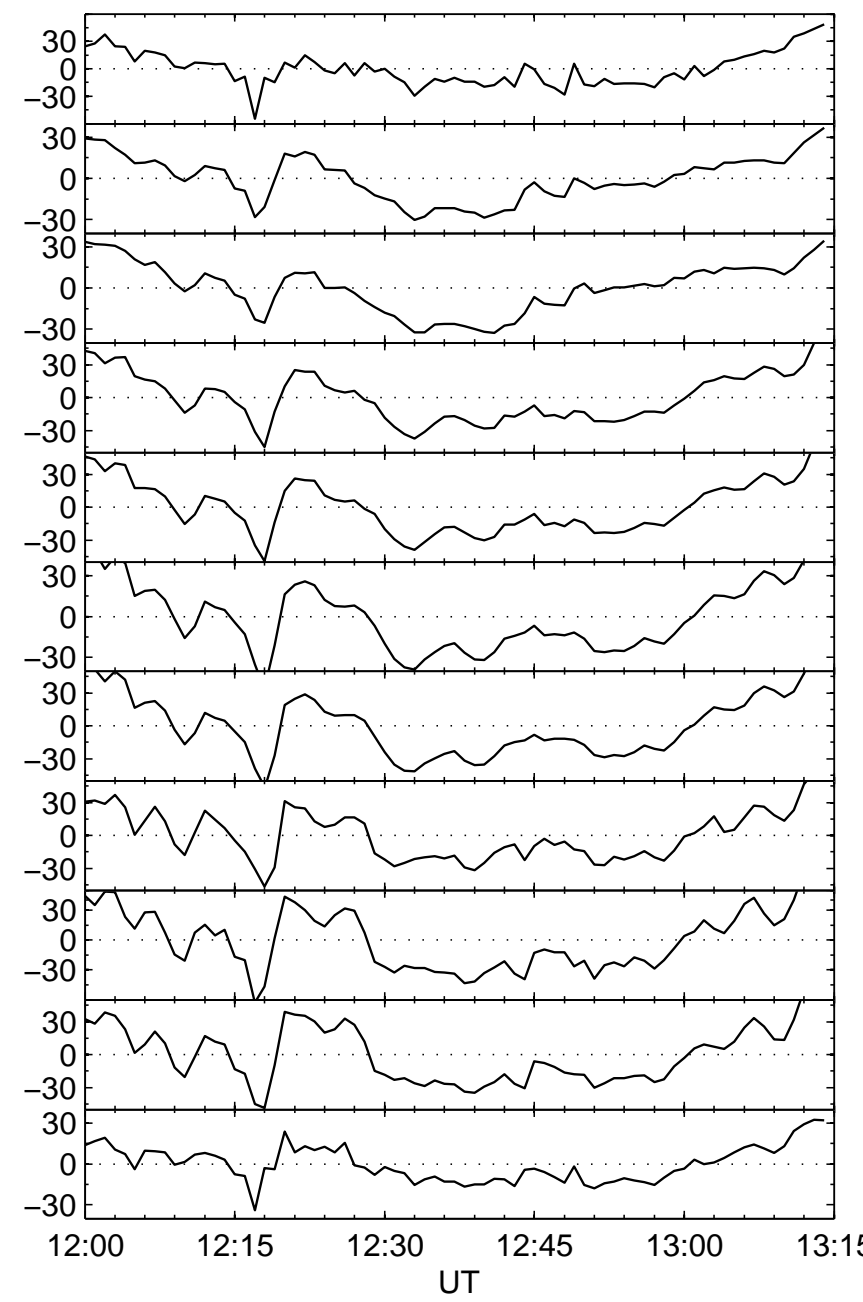

(b) PSD (arbitrary units)

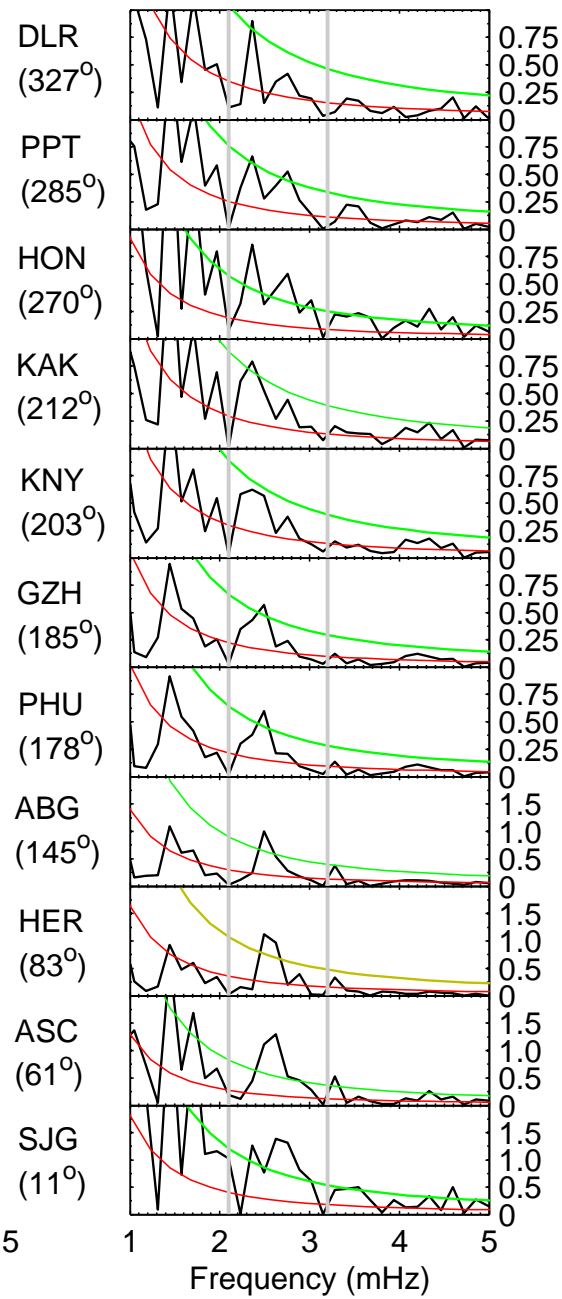

Fig. 6. Same as Fig. 2 but in time interval 12:00-13:15 UT on 31 October 2005. Frequency range 2.1-3.2 mHz is selected due to globally high and statistically significant spectral peaks in this band around the globe.

\subsubsection{March 2005 event}

During the initial phase of a storm (minimum Dst $\simeq-65 \mathrm{nT}$ ) on 6 March 2005 intense substorm $(\mathrm{AL}<-1000 \mathrm{nT})$ was triggered in the time interval 15:00-18:00 UT. In this time duration, periodic oscillations in the frequency range 0.6$1.1 \mathrm{mHz}$ (period range $\sim 15-28 \mathrm{~min}$ ) were globally identified. As shown in the right panel of Fig. 5d, power spectra of $\Delta H$ observed at HER and HON show high power in this frequency range above $95 \%$ confidence level. The magnetic longitude profile of $\Delta H_{\text {asym }}$ in this spectral band shows the westward propagation with $V_{\text {ap }} \sim 360^{\circ} / 20 \mathrm{~min}$, which starts around 15:00 UT and after three or four cycles the propagation pattern becomes random as shown in the left panel of Fig. 5d.

\subsection{Eastward propagating event}

\section{October 2003 event}

The recovery phase of Halloween storm of 29-31 October 2003 is believed to be characterized by an abundance of relativistic electrons (energy $\sim \mathrm{MeV}$ ) in the inner magnetosphere (Loto'aniu et al., 2006). This event has been specially included to examine the possible involvement of electron drift modes.

For the event of 31 October 2003, high amplitude Pc5 ULF waves were globally observed during the recovery phase of super intense storm (minimum Dst $-383 \mathrm{nT}$ ). Shown in Fig. 6a, are the $\Delta H$ values in time interval 12:00-13:15 UT observed at globally distributed 11 stations. It is evident from figure that similar oscillations were globally observed during the event. Power spectra of $\Delta H$ show common 
(a)
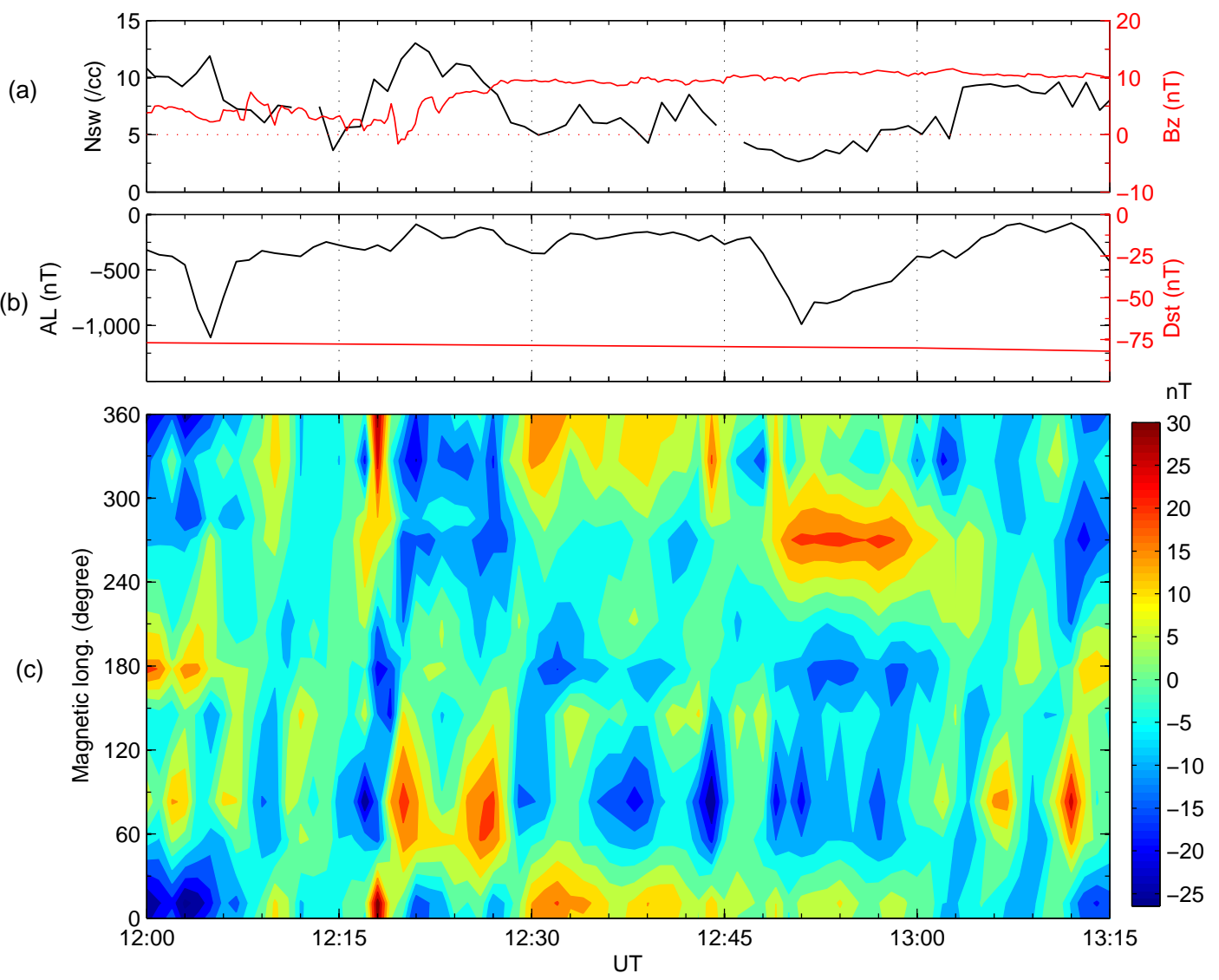

Fig. 7. Same as Fig. 3 but in time interval 12:00-13:15 UT on 31 October 2005. However, contour plot of $\Delta H_{\text {asym }}$ indicates disturbance propagating eastward in longitude unlike the westward propagation shown in Fig. 3c.

spectral peaks in the frequency range $2.1-3.2 \mathrm{mHz}$ clearly above $95 \%$ confidence level at all the stations, except KNY.

Figure 7 a shows solar wind density and IMF $B_{\mathrm{Z}}$ conditions during the event as observed by ACE satellite located at $X \simeq 232 R_{\mathrm{E}}, Y \simeq 26 R_{\mathrm{E}}, Z \simeq-37 R_{\mathrm{E}}$ in GSM coordinates. The interplanetary observations are time-shifted by $25 \mathrm{~min}$ taking into account the travel time of the solar wind at an average propagation speed of $\sim 993 \mathrm{~km} \mathrm{~s}^{-1}$ from the location of the satellite to the ground. Clear intensifications of auroral electrojet were observed during recovery of the storm as shown in Fig. 7b.

In Fig. 7c, X-axis represents time in UT, Y-axis represents magnetic longitude and the variations in $\Delta H_{\text {asym }}$ for the raw data have been colour-coded. If one follows the rising or falling tones, one will clearly identify the eastward propagation of disturbance in the raw data itself. Moreover, if one looks at a particular longitude (say around 85 degree), the time difference between two successive maxima or minima is around 6-7 min. However, one cannot ignore the presence of disturbances of other time scales. The plot clearly shows the dominance of 6-7 min disturbances as also seen in the spectra of raw data in Fig. $6 \mathrm{~b}$.
Now to bring out the propagation characteristic of the mode appearing at all the stations, we perform a bandpass filtering on the raw data in the frequency range $2.1-3.2 \mathrm{mHz}$ and examine the asymmetric variations (obtained by subtracting out the zonal mean at each instant) for the mode. Figure 8 shows an unambiguous eastward propagating mode with $V_{\text {ap }} \sim 360^{\circ} / 7 \mathrm{~min}$.

\section{Discussion and conclusions}

The charged particles in the Earth's magnetosphere undergo a slow azimuthal drift motion as an effect of the gradient and curvature of the dipole magnetic field and constitute the ring current (Williams, 1985). The ions drift in westward direction, whereas electrons drift azimuthally eastward. Significant contribution to the ring current comes from ions typically in the energy range of $20-300 \mathrm{keV}$ (Wolf, 1995). As a consequence of westward drifting energetic ions, the ring current flows westward in direction and depresses the low latitude geomagnetic field. During magnetic storms, low latitude magnetic disturbance is often asymmetric in local time, with the maximum depression near dusk and the minimum 


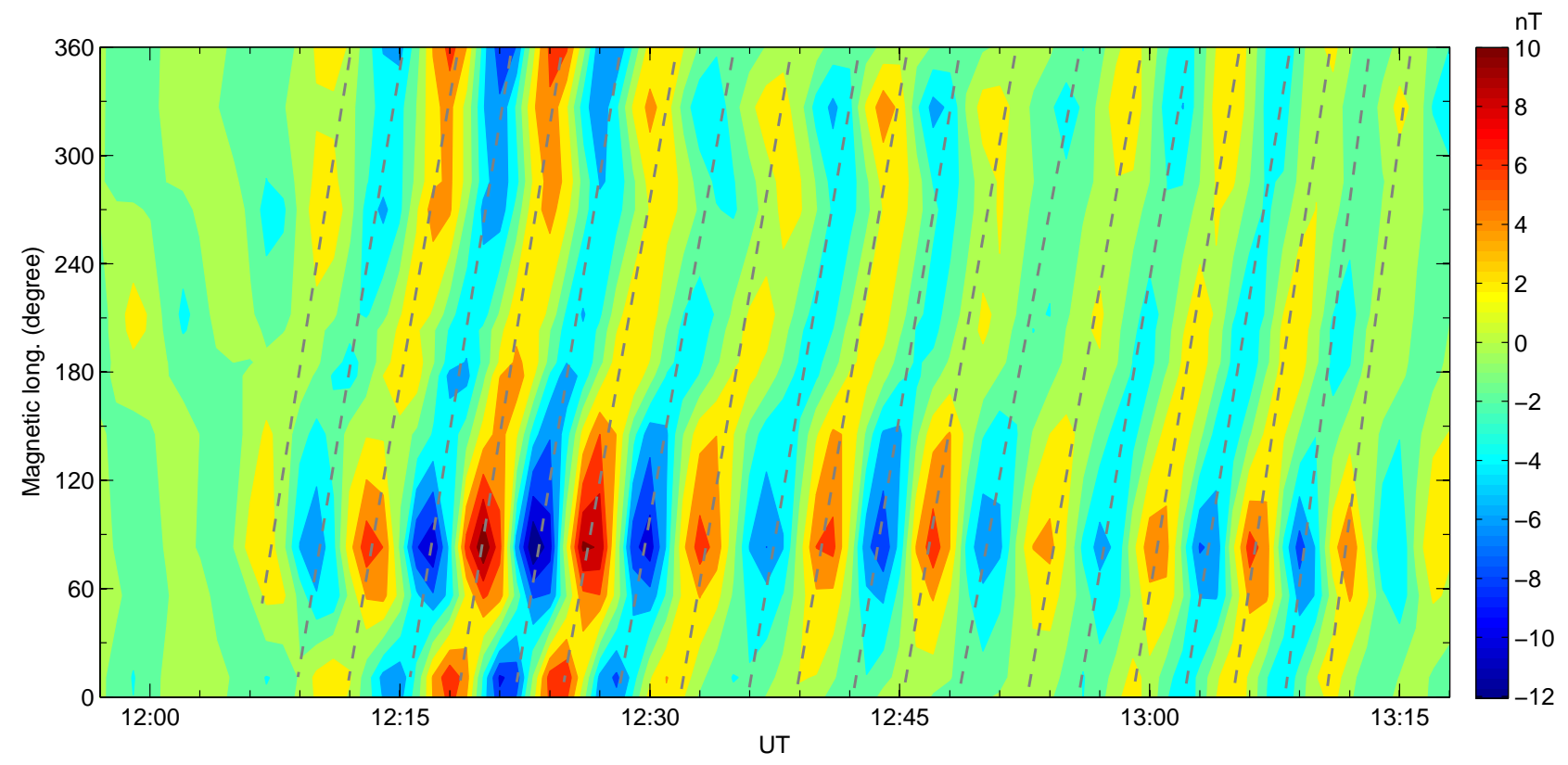

Fig. 8. Same as Fig. 4 but in time interval 12:00-13:15 UT on 31 October 2005. The unambiguous eastward propagation of the mode (frequency range $2.1-3.2 \mathrm{mHz}$ ) indicates the effect of electron drift.

depression on the dawn (Akasofu and Chapman, 1964; Love and Gannon, 2010). Due to rotation of the Earth, there is $24 \mathrm{~h}$ periodicity in local time, which is clearly seen in asymmetric disturbance during long-lasting storms.

Density and temperature gradients in magnetically confined plasma give rise to universal instability called as drift waves (Horton, 1999; Chen, 2008). The instability mechanism can spontaneously convert particle thermal energy into wave energy and the electromagnetic fields from the waves in turn can cause stochastic motion of the constituent plasma particles (Horton, 1999). The drift waves largely control the transport of plasma across the magnetic field (Southwood and Hughes, 1969; Horton, 1999).

An approximate drift frequency of ring current particles can be computed using the following equation (Baumjohan and Treumann, 1997)

$f_{\mathrm{d}}=\frac{3 L W}{\pi q B_{\mathrm{E}} R_{\mathrm{E}}^{2}}\left(0.35+0.15 \sin \alpha_{\mathrm{eq}}\right)$

where $L$ is L-shell parameter, $W$ is the particle energy, $q$ is charge of the particle, $B_{\mathrm{E}}$ is the equatorial magnetic field on the Earth's surface, $R_{\mathrm{E}}$ is the radius of the Earth and $\alpha_{\mathrm{eq}}$ is the equatorial pitch angle. Drift frequencies of the ring current particles depend on the energy, radial location and pitch angle. Drift frequencies of the ring current ions have a wide range $\sim 0.01$ to $1.0 \mathrm{mHz}$. Frequencies of the observed modes propagating westward, presented in Figs. 4 and 5, fall in the range of ion drift.

Though ring current is dominated by ions, occasionally contribution of electrons to the ring current becomes dominant. Large amplitude and long-lasting Pc5 ULF waves play a fundamental role in relativistic acceleration of drifting electrons through drift-resonant interaction during geomagnetic storms (Rostoker et al., 1998; Elkington et al., 2003). Loto'aniu et al. (2006) reported the abundance of relativistic electrons (energy $\sim 2-6 \mathrm{MeV}$ ) in the inner magnetosphere ( $L \simeq 2$ ) during the Halloween storm of 29-31 October 2003 . The accelerated eastward drifting electrons are expected to enhance the asymmetry in magnetic field that will propagate eastward in longitude as shown in Fig. 8. Calculated drift frequencies for the relativistic electrons (using Eq. 1) near $L \simeq 2$ varies between $\sim 1-4 \mathrm{mHz}$. Frequency of the mode propagating eastward fall in this range suggesting the possible association with electrons drift.

Westward (eastward) wave drift speeds will be regulated by energetic ions (electrons) at the location of their generation. The observed wave speeds on ground, therefore, vary from case to case but they fall within the window of expected values in the magnetosphere. Different apparent speed of azimuthally propagating modes on the ground can be attributed to the fact that actual mode oscillations could be at different radial locations characterized by different ion (electron) drift speeds.

It is known that all super intense storms do not produce ample relativistic electrons (cf. Loto'aniu et al., 2006). For example, 20 November 2003 storm was more intense than the October 2003 storm, but extremely high flux of relativistic electrons penetrated to lower L-values ( $L \simeq 2$ ) during the storm of October 2003 unlike November 2003 event. Similar analysis was performed for November 2003 event but we do not find unambiguous eastward propagation as seen for the 
October event; rather westward propagation was observed in certain longitude region. We believe, for the eastward drift to be clearly observed eastward drifting relativistic electron flux has to be high enough.

It should be emphasized that these longitudinal structures are associated with currents corresponding to propagating source and do not correspond to the longitudinal structure of ambient ring current. In fact, these modes are globally available and can be identified through a simple analysis of the type undertaken here. Presence of these modes have not been demonstrated so far in spite of the obvious practical use of the mode in diagnostics of the magnetosphere from groundbased studies. In this study we selected smaller ground magnetic data base (year 2003-2005). We realize the importance of establishing the morphology as well as long term statistics of these observed modes. However, this is the first attempt to identify these modes from ground-based magnetic data. We, therefore, decided to focus on a smaller data base. Larger data base of ground magnetic observations could prove to be an effective tool for categorisation of such modes associated with storms. While only ground observations have been used in this study, it will be worthwhile to use simultaneous ground and satellite data to establish the morphology of such modes. Statistics from larger data sets in corroboration with interplanetary conditions could throw light on interplanetary and magnetospheric conditions against which westward and eastward propagating modes show their presence.

Acknowledgements. We thank INTERMAGNET (www. intermagnet.org) for providing ground magnetic field data. Interplanetary observations made by ACE satellite were taken from CDAWeb (http://cdaweb.gsfc.nasa.gov/) and geomagnetic indices were made available by WDC, Kyoto.

Topical Editor I. A. Daglis thanks two anonymous referees for their help in evaluating this paper.

\section{References}

Akasofu, S.-I. and Chapman, S.: On the asymmetric development of magnetic storm fields in low and middle latitudes, Planet Space Sci, 12, 607-626, 1964.

Allan, W., Poulter, E., and Nielsen, E.: STARE observations of a Pc 5 pulsation with large azimuthal wave number, J. Geophys. Res., 87, 6163-6172, 1982.

Baumjohann, W. and Treumann, R. A.: Basic Space Plasma Physics, Springer, New York, 1997.

Chan, A. A., Xia, M., and Chen, L.: Anisotropic Alfvén-ballooning modes in Earths magnetosphere, J. Geophys. Res., 99, 1735117366, doi:10.1029/93JA03353, 1994.

Chen, F. F.: Introduction to Plasma Physics and Controlled Fusion, Imperial College Press, London, 2008.

Cummings, W. D.: Asymmetric ring currents and the low-latitude disturbance daily variation, J. Geophys. Res., 71, 4495-4503, doi:10.1029/JZ071i019p04495, 1966.

Elkington, S. R., Hudson, M. K., and Chan, A. A.: Resonant acceleration and diffusion of outer zone electrons in an asymmetric geomagnetic field, J. Geophys. Res., 108, 1116 , doi:10.1029/2001JA009202, 2003.

Frank, L. A.: Direct detection of asymmetric increases of extraterrestrial 'Ring Current' proton intensities in the outer radiation zone, J. Geophys. Res., 75, 1263-1268, doi:10.1029/JA075i007p01263, 1970.

Hasegawa, A.: Drift mirror instability in the magnetosphere, Phys. Fluids, 12, 2642-2651, 1969.

Horton, W.: Drift waves and transport, Rev. Mod. Phys., 71, 735778, 1999.

Iyemori, T.: Storm-time magnetospheric currents inferred from mid-latitude geomagnetic field variations, J. Geomag. Geoelectr. 42, 1249-1265, 1990.

Lin, C. S. and Barfield, J. N.: Azimuthal propagation of storm time Pc 5 waves observed simultaneously by geostationary satellites GOES 2 and GOES 3, J. Geophys. Res., 90, 11075-11077, 1985.

Loto'aniu, T. M., Mann, I. R., Ozeke, L. G., Chan, A. A., Dent, Z. C., and Milling, D. K.: Radial diffusion of relativistic electrons into the radiation belt slot region during the $2003 \mathrm{Hal}$ loween geomagnetic storms, J. Geophys. Res., 111, A04218, doi:10.1029/2005JA011355, 2006.

Love, J. J. and Gannon, J. L.: Movie-maps of low-latitude magnetic storm disturbance, Space Weather, 8, S06001, doi:10.1029/2009SW000518, 2010.

Rostoker, G., Skone, S., and Baker, D. N.: On the origin of relativistic electrons in the magnetosphere associated with some geomagnetic storms, Geophys. Res. Lett., 25, 3701-3704, 1998.

Southwood, D. J., Dungey, J. W., and Etherington, R. J.: Bounce resonant interaction between pulsations and trapped particles, Planet. Space Sci., 17, 349-361, 1969.

Sugiura, M.: Hourly values of equatorial Dst for IGY., Ann. Int. Geophys. Year, 35, 945-948, 1964.

Takahashi, K.: Multisatellite studies of ULF waves, Adv. Space Res., 8, 427-436, 1988.

Takahashi, K., Higbie, P., and Baker, D.: Azimuthal propagation and frequency characteristic of compressional Pc 5 waves observed at geostationary orbit, J. Geophys. Res., 90, 1473-1485, 1985.

Takahashi, K., Lopez, R., McEntire, R., Zanetti, L., Kistler, L., and Ipavich, F.: An eastward propagating compressional Pc 5 wave observed by AMPTE/CCE in the postmidnight sector, J. Geophys. Res., 92, 13472-13484, 1987.

Walker, A. D. M. and Nielsen, E.: Stare observations of an eastward propagating Pc5 pulsation with large azimuthal wavenumber, Geophys. Res. Lett., 11, 259-262, 1984.

Walker, R. J. and Russell, C. T.: Solar-wind interactions with magnetized planets, in: Introduction to Space Physics, edited by: Kivelson, M. G. and Russell, C. T., Cambridge University Press, New York, 164-182, 1995.

Walker, A., Greenwald, R., Korth, A., and Kremser, G., STARE and GEOS 2 Observations of a Storm Time Pc 5 ULF Pulsation, J. Geophys. Res., 87, 9135-9146, 1982.

Williams, D. J.: Dynamics of the earth's ring current - Theory and observation, Space Sci. Rev., 42, 375-396, 1985.

Wolf, R. A.: Magnetospheric configuration, in: Introduction to Space Physics, edited by: Kivelson, M. G. and Russell, C. T., Cambridge University Press, New York, 288-328, 1995. 